\title{
UNDERGROUND DISTRIBUTION SYSTEMS
}

\author{
BY G. J. NEWTON
}

Abstract of Paper

The object of this paper is to show the importance of properly designing an underground distribution system for the district it serves and the particular service it is to supply. Simply placing the wires underground does not constitute an efficient system.

Underground distribution is the ultimate solution of the distribution problem that confronts every Electric Light and Power company operating in progressive towns and cities. The excessive cost of this class of construction, as compared with aerial construction, and the permanent nature of the system, warrant a careful study of the conditions and justifies a reasonable expense in the development of suitable plans for the system.

The financial success of an electrical undertaking depends on supplying efficient and reliable service in an economical manner, and in order to secure this result the distribution system must be carefully designed and properly installed.

The automatic substation, when perfected and adopted, will not only permit a great reduction in the number of ducts required and a lower first cost, but will provide more reliable service and bring underground distribution within the reach of many small companies where the cost of this class of service would not be warranted under the former conditions.

The suggestions offered in this paper are based on many years experience and are made with a sincere desire to aid those interested in this class of work, particularly in the design and installation of the first system in the smaller cities.

\section{$\mathrm{T}$} HE FOLLOWING facts and suggestions are based on many years experience with underground distribution systems, and are stated in the following article with the intention of showing the importance of careful and intelligent design as related, not only to the first cost, but to the economical operation and ultimate value of the completed system.

An inspection of many systems has made it evident to the writer that improper design is responsible for more faults than is poor construction, and it is with a sincere desire to aid others interested in this work, to avoid such mistakes in the future, that these suggestions are offered. 
No two systems are entirely alike, and the conditions are different in every place; it is, therefore, impossible to formulate any definite rules that will apply under all conditions. The engineer must be guided by good judgment, based on experience, and a thorough study of the conditions in order to secure satisfactory results.

Owing to the increasing demand for electrical energy, and the serious objection to the unsightly and dangerous overhead wires and poles, underground systems of distribution have become a necessity in many places where the expense of this class of service would not have been considered warranted under former conditions.

Underground distribution is very expensive, as compared with overhead construction, and in many cases, particularly in the smaller cities, the first cost is of vital importance; a carefully worked out design is therefore necessary in order to derive the greatest benefit from the money expended. Many of the present systems have not been designed with the care, and attention to detail, that their importance deserves and frequently the cost of the system has been entirely out of proportion to its ultimate value.

The first installation of an underground system is made necessary by an order of the city authorities compelling the removal of poles and wires from certain sections of the city or by the desire of the operating company to improve the service and secure greater facilities in a district where the demand for light and power has reached a point that this class of service is warranted.

In either of the above cases, and in fact, practically in all cases in this country, underground systems are never installed until long after the district has been supplied by an overhead system. As a general rule, all overhead systems are the result of a series of extensions and changes, rather than the development of any systematic plan of distribution, and are seldom based on efficient or economical methods.

If it were possible to design and install an underground system at the start of an electrical undertaking the problem would be much simplified, as the station and consumers equipment could be selected, and the whole system designed for the most efficient results. Unfortunately the conditions are never so favorable, and the distribution engineer is confronted with many conditions over which he has no control, but must consider in making his plans. 
Distribution problems are, therefore, usually very complex and permit of several methods of being solved. It is only by a careful study of the conditions and foresight as to the future requirements of the system that a satisfactory, economical and efficient design can be developed.

The conditions under which underground cables and equipment operate are more severe than on overhead systems, and a thorough knowledge of these conditions is absolutely necessary, and must be kept in mind, in selecting cables and equipment and designing the conduit system for their installation. Overhead wires can be, and frequently are, operated far above their rated capacity, without any serious danger, but underground cables and equipment must be operated within certain definite limits in order to avoid serious damage, if not total destruction.

Economy of distribution is equally as important as economy in production, particularly at the present time, when practically all public utility companies are regulated, to a greater or less extent, by state or municipal commissions. First cost is not, therefore the only factor that should be considered, as economical operation and reliability of service are equally as important in the financial success and growth of the business.

Except in the large companies, there is probably no branch of the business that has been given less thought. and study than underground work; in many cases the principal object evidently has been to get the wires out of sight at the least possible expense, with no attempt being made to improve the system of distribution and little or no regard for the future development of this class of service.

The operation of an underground system, when properly designed, installed, and maintained guarantees the most reliable and efficient service of any method of distribution ever employed; the financial benefit, directly due to this class of service is, in many cases, a proof of the wisdom of its installation.

While it is admitted that underground systems are expensive to install, still it must be remembered that a conduit system is a permanent structure, has little or no depreciation; on the contrary it will increase in value as the importance of the section it serves is developed. Considering the first cost, permanent nature of the undertaking, and importance of economical and reliable service, it is advisable to make a thorough study of the conditions and future requirements of the service on which to base a design of the proposed system. 
In designing an underground distribution system there is one important fact that must always be considered-the system should be designed to serve the entire district that can reasonably be expected to ever require this class of service. Such a design permits of a systematic scheme being developed for the whole district, uniform methods of construction, and standardization of equipment.

If this method is followed it is then possible to install any section, from time to time as the service demands, and each completed section will form a part of the whole general scheme and eventually develop into a system rather than a collection of more or less useful sections of conduit.

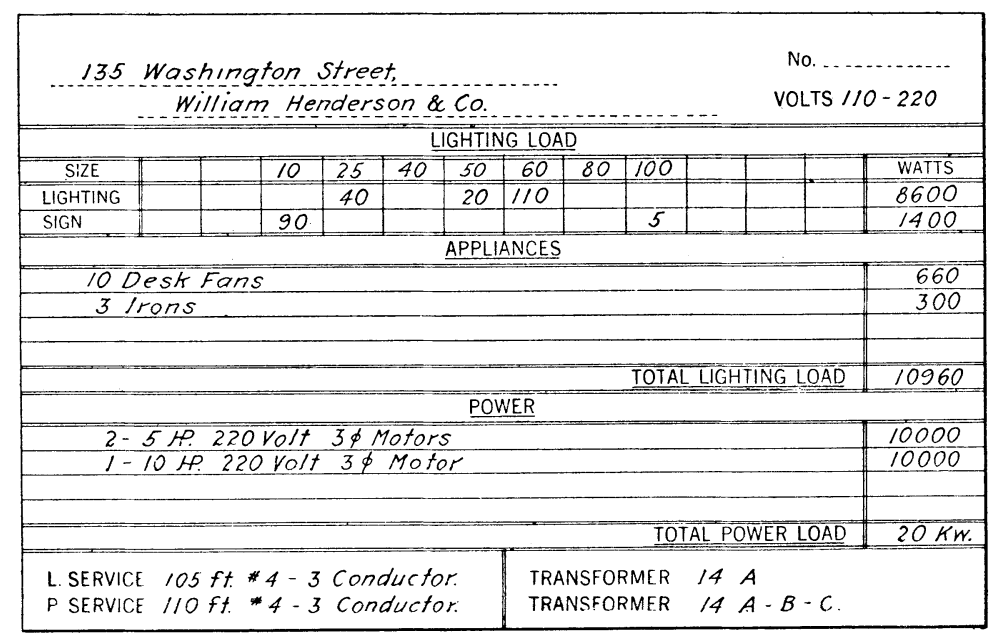

FIG. 1

It is not the object of this article to show each step in the design of any particular system but rather to point out certain important features to be kept in mind and offer suggestions as to the general method to be adopted; it is only by a thorough study of each case that the best methods can be determined.

The first step in designing an underground distribution system is to secure an accurate load record for each consumer in the proposed underground district. This record should be kept on cards similar to Fig. 1; where there is a large power load in the district it is advisable to make separate records for the lighting and power loads, using different colored cards for each record.

The card shown in Fig. 1 is simply a sample, and the best 
arrangement of the inventory on the cards will depend on the requirements of each particular system.

The reverse side of the cards can be used for showing the number and location of the transformer supplying the service lateral, consumers fuse box and other information connected with each consumers service.

These cards if properly corrected will form a permanent record of great value in making future changes and balancing the load on the distribution system.

The men securing the load record should be provided with paper pads printed the same as the cards and the permanent card record can be made in the office from these slips and the cards be kept clean and neat.

A careful inspection should be made of each building to determine the most suitable location for the new underground lateral in order to reduce the cost of changing the inside wiring as much as possible. Except in the case of very heavy loads or consumers where emergency service must be provided for, it is advisable to supply all of the consumers in a building from one lighting and one power lateral, this reduces the number of laterals, handholes, and fuse boxes and permits using the least amount of copper by taking advantage of the diversity of a group of consumers.

The lighting and power load can be plotted on one drawing as shown in Fig. 2 or the loads can be plotted on separate plans, the latter method is best as the plans for each system can then be kept separate.

The load maps for each system should show the total load, both in the underground district and outside of it, that is to be supplied by cables in the conduit system from the power house so that ample conduit space can be provided and the most suitable routes and sizes of feeders determined.

Having the lighting and power loads and a map showing the street light system, the next step is to determine the most suitable plan of distribution to be adopted, this may be called the critical point in the design of a distribution system, for on the decision depends not only the first cost of the installation but the reliable, efficient and economical operation of the distribution system.

There are two general schemes of distribution:

1. To supply the whole city from one power house.

2. Divide the city into districts and supply each from substations, or rather from the power house and substations. 
In many of the older systems the first method was used and a large number of ducts were installed, in one trench from the power house, to serve the whole city, or at least that portion that was to be supplied by underground eventually. This necessitated providing a large number of spare ducts, a large percentage of which remained idle for years and not infrequently resulted in too many ducts in some places and too few in others.

Not only was the first cost of such a system excessive but the manholes were almost invariably too small to accommodate the number of cables that could have been installed in all of the ducts had there ever been use for them. The most serious objection to this plan is that the losses due to the heating of so many cables in one conduit run are excessive and materially reduce the carrying capacity of the cables, particularly in cables occupying the inner ducts.

Another serious objection to this method is that a burn-out on one cable is practically certain to damage adjacent cables and cause interruption of service over a considerable area. Faults on underground systems usually affect more consumers than on an overhead system and require more time to repair, therefore, no system should be considered that does not permit being sectionalized and have reasonable emergency facilities provided for restoring service with the least possible delay.

The objections to the first plan, as stated above, preclude its adoption except in very small cities where the area to be served by underground distribution is limited, and the total number of ducts installed in one trench will not be excessive.

The second method of distribution, when properly designed, avoids all of the objectionable features of the first method and is particularly adapted to the modern practise of installing substations supplied by high-tension feeders, as each district is practically operated separate from the others and with suitable emergency feeders and switching equipment permits each district to assist the others in case of necessity.

The old saying "That you should not put all of your eggs in one basket" is particularly true if we change the words slightly"You should not put all of your feeders in one trench or manhole" and the distribution engineer will be wise to keep this warning in mind as far as the requirements of the case will permit.

Reliable service and economical distribution are absolutely necessary for the financial success of every light and power company. Reliability depends on the following conditions: 
1. The best material, equipment and workmanship.

2. Proper selection of material and equipment for the service it is to supply.

3. Efficient protective apparatus, judiciously installed.

4. Sectionalizing apparatus properly located.

5. Continuity of supply, by feeders over different routes or an arrangement that will provide at least two sources of supply for the network.

6. Regular and systematic inspection of the distribution system by competent men.

7. Accurate plans and records of the distribution system so that changes, additions and extensions can be made to the best advantage with the least possibility of error.

Economical operation depends upon a reasonable first cost, in addition to all of the above conditions, and where a system is designed at first for a whole city (keeping in mind future substations) it is possible to reduce the number of ducts and manholes to a minimum, install sections as the business warrants and extend the ultimate cost over a considerable period.

Keeping the above facts in mind the actual design of an underground distribution system should be made on the following general plan. Assuming that the first underground installation is to supply a district similar to that shown in Fig. 2, and that later this district will be extended a block or two in each direction and supplied from the main station.

While it is admitted that it is not possible accurately to foretell where substations will be located in the future, still a study of the conditions will generally permit a reasonable assumption to be made and if separate conduit is to be installed later for high-tension feeders this part of the work does not enter into the first design except in a general way.

After making the load maps for the lighting and power systems and also a map showing the location of the street lights it is a good plan to first layout the street light circuits, for assuming that all wires in the district must be placed underground it is evident that conduit must be installed to reach every light.

The location of the street lights is determined by the city authorities and can seldom be altered enough to materially change the conduit arrangement, therefore, by designing this system first it will give a general idea of where the conduit must be installed and keeping this plan in mind it is frequently possible to arrange the secondary mains so as to utilize the same routes 


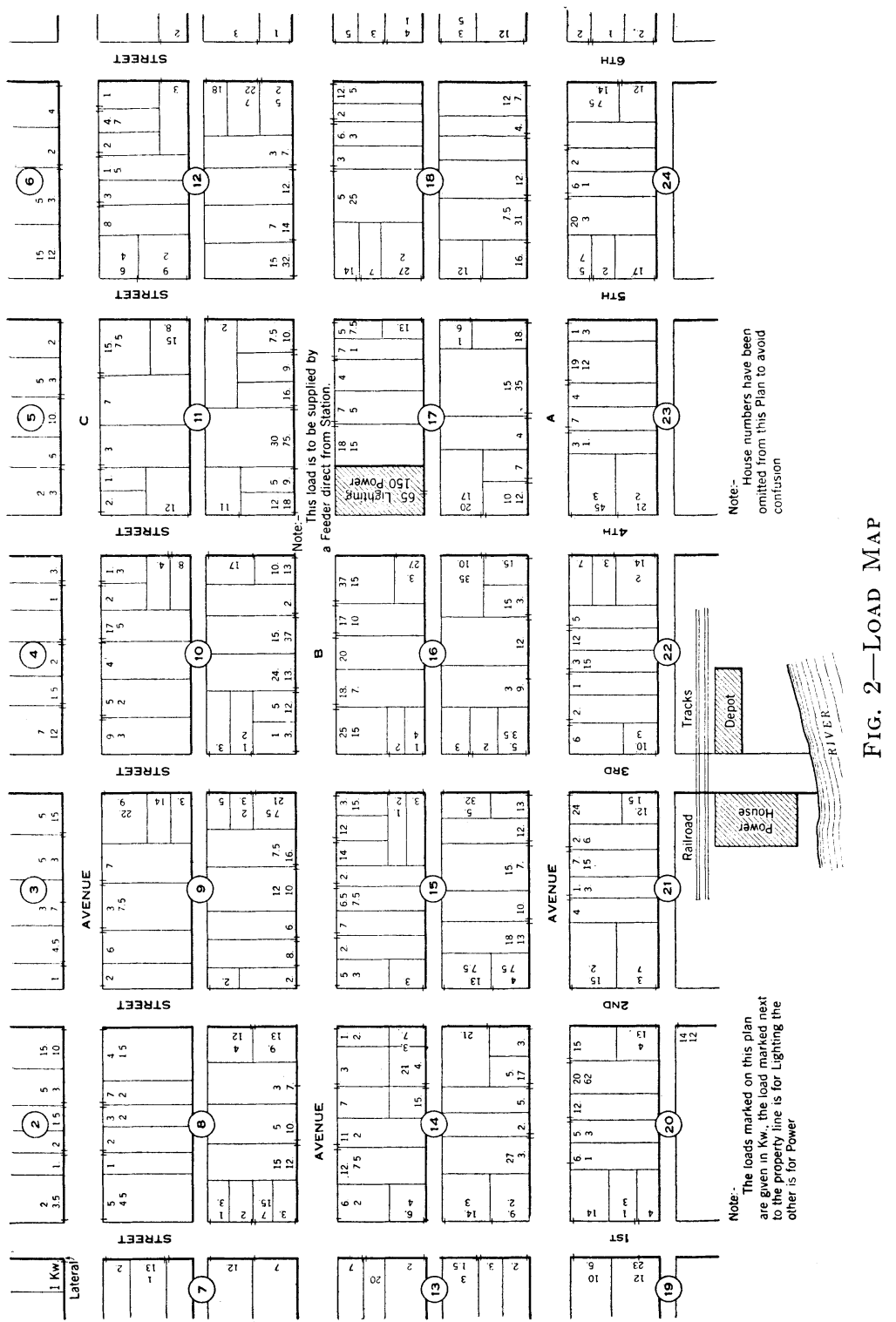


(particularly in alleys and the less important streets) so as to avoid considerable conduit construction.

The proposed location of the laterals in each building should be shown on the plan for the secondary systems for light and power. A study of these locations together with the street light conduit layout will often show where slight changes in one or the other will permit considerable saving, even when changing some laterals will increase the cost of the inside wiring.

Owing to the fact that the grouping of consumers, in a district, will usually be different on an underground system than it was on the original overhead system it is practically impossible accurately to determine what the demand and diversity factors will be for the new system. A distribution system for either lighting or power usually consists of the following sub-divisions:

Primary feeders to centers of distribution.

Secondary feeders supplying the transformers.

Secondary mains supplying the service laterals.

Service laterals supplying the consumers.

In small systems the secondary feeders are not required, as the transformers are connected directly to the primary feeders.

The size of cables to use for the laterals is easily determined, the principal object is to restrict the number of sizes of cable as much as possible, using about three sizes for the whole system, and if possible, making the largest size used for laterals the same as one of the sizes used for secondary mains.

Aside from the laterals it is evident that the secondary mains receive less benefit from the diversity factor than any other part of the system. It is also evident that any increase in the load will directly affect the mains which must be large enough to maintain satisfactory voltage for all consumers connected to them.

On the one hand is the diversity factor tending to reduce the size of the mains and on the other hand the probable increase in load which must be provided for, tending to increase the size of the mains. As not only the first cost but the interest on the investment depends on the size of the copper, it is important that these two conditions be given careful consideration and it is in cases of this kind that the engineer must be guided by experience and his knowledge of the situation.

There is one point that should be remembered in determining the size of cable to install for secondary mains, particularly where they serve a number of consumers in a business district. 
Owing to the fact that the service laterals are spliced directly to the mains at frequent intervals it is very expensive to replace them and the old cable, being in short lengths, is of little or no use except for its junk value; it is therefore advisable to make all secondary mains of ample size to provide for the total load that can reasonably be expected and use the best kind of cable, either varnished cambric or rubber insulated, for all secondary mains and laterals that terminate in junction or fuse boxes.

The load in the district should be divided as equally as possible into a suitable number of distribution centers so that one size and style of cable can be used for all of the feeders, as this permits standardizing the equipment and requires less cable being kept in stock for emergency purposes.

The feeders being generally small cable and having few or no taps on them can easily be replaced by larger cable and the.old cable is in sufficient lengths to be used elsewhere. Instead of installing a larger cable to replace a loaded one it is generally better to install an additional feeder to another center of distribution, using the standard size of cable.

Where the requirements of the system demand the use of twoconductor cable it is advisable to have it made up in round form instead of the flat, or figure 8 style, as it is practically impossible to train this latter style without kinking it.

A careful study of the conditions under which underground distribution systems operate, particularly in medium size or smaller cities, has convinced the writer that the safest guarantee of reliable, efficient, and economical operation is to install cable and equipment, as far as the conditions will permit, under the following general rules.

Service Laterals. Use either cambric or rubber insulated cable, spliced directly to the secondary mains, and terminated in watertight fuse boxes on the consumers property. (The number of laterals taken out at one splice will depend on the system; for single-conductor cables four laterals can be taken out, but two is about the limit where three-conductor mains and laterals are used.)

Secondary Mains. Make these cables of ample size to provide for all the growth that can reasonably be expected. Use either varnished cambric or rubber insulated cable for all secondary work where cables terminate in subway equipment.

Primary Feeders. These cables derive the most benefit from the diversity factor, are comparatively long lengths, and have 
few taps on them, therefore are less subject to damage than the rest of the cables and are easily replaced with small financial loss. Small reserve capacity is all that need be provided for this class of cables.

Paper insulated cable can be used to advantage frequently at considerable saving providing that the ends are properly terminated in compound-filled potheads or varnished cambric or rubber insulated tails used for connecting to the equipment.

Personally, the writer does not approve of using any paper insulated cable on distribution systems, except on cases where the emergency facilities are such that the failure of a feeder cannot cause a serious interruption to the service.

In small companies, where competent cable men are not always available, the use of paper insulated cable on the distribution system is not advisable, it is however, well suited for high-tension feeders and tie-lines.

Subway Equipment. Due to the liability of being submerged occasionally and the limited space usually available, for its installation, subway equipment is probably the most prolific cause of trouble on underground distribution systems, and the greatest care must be used in selecting and installing it.

The best insurance against trouble from this cause is to provide reliable sewer connections to. all manholes and vaults in which subway equipment is located. Separate the primary and secondary equipment by placing the transformers, primary fuses and switches in a vault (preferably located under the sidewalk adjacent to the manhole in which the secondary junction boxes are located.) This arrangement reduces the length of the secondary mains, which are usually large expensive cable, and lessens the liability of a burnout on the primary equipment damaging the secondary network. See Fig. 3.

The object in placing the vaults under the sidewalk is that it is seldom possible to secure sufficient room in the street, also there is less liability of the vaults being flooded from surface water and they are more accessible in the winter when the ground is covered with ice and snow. This method of construction is more expensive than placing all of the equipment in the manholes but the added security is well worth the expense on an important installation.

Subway transformers should not be set on the floor of the vault but should be raised so that the air can circulate under and around them. Where more than $200 \mathrm{kw}$. of transformer 
capacity has to be installed in one vault it is advisable to provide ventilating pipes from the vault to a pole or side of a nearby building.

Subway junction and fuse boxes should not have slate or marble bases, but use ebonite or similar material that will not absorb moisture. All boxes should be subjected to an insulation test before being installed. Barriers should be provided between terminals of opposite polarity.

The iron work of all subway equipment should be permanently grounded to a reliable ground rod, plate, or if possible, to the city water pipe system. In large vaults, where there is considerable equipment, at least two ground connections should be provided.

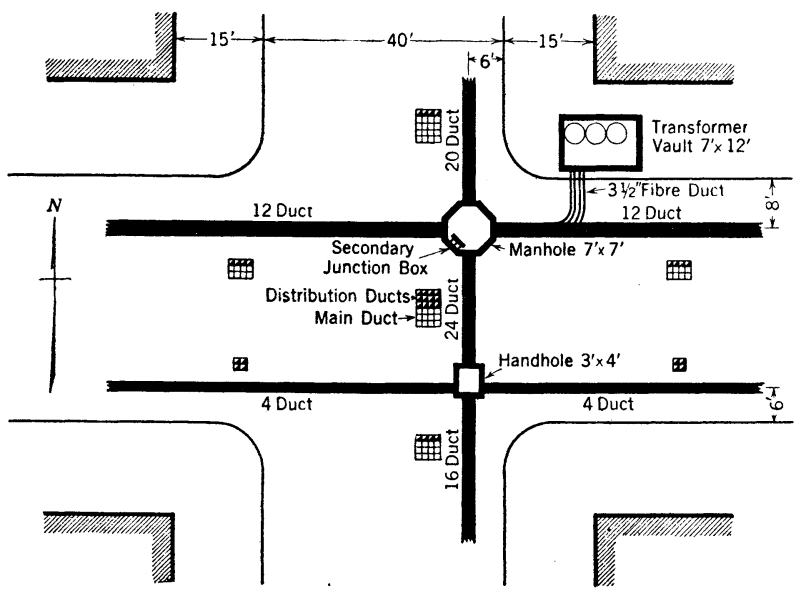

FIG. 3

Installing Cable. Assuming that all cable has passed the usual factory test, it is seldom necessary to subject it to another test before being installed unless there is some evidence that it has been damaged in transit. The conditions under which the cable is purchased and installed will, however, generally decide this point.

Use skids in loading and unloading reels, never drop them off of the truck. Place reels as near the point where they are to be used as possible. When reels must be left on the street for some time they should be securely blocked or preferably wired to a pole to prevent their being rolled about. Care should be taken not to place reels where they will interfere with hydrants, or obstruct manholes, water gates or traffic. 
Never handle paper insulated cable when it is cold. In cold weather it should be kept in a warm place until it is to be installed. Paper cable should not be bent shorter than eight times its diameter and should be warmed before bending.

Always provide sufficient men and power to safely handle cable during installation, when the cable is started in the conduit try to maintain an even steady rate of pulling. For heavy cable it is advisable to use grease or powdered soapstone.

Ends of cables should be kept sealed until ready to be spliced. Cables should not be left hanging from the duct mouth, but should be supported on hangers with as little bending as possible. The final bending and training of the cables should be done by the splicer when joining the sections.

When installing a new system, all lengths of cable should be bonded together temporarily as soon as they are installed. As soon as the cable system is completely connected up tests for electrolysis should be made of the whole system and proper measures taken to protect the cables in case of necessity.

The arrangement of cables and equipment in the manholes and vaults must be carefully planned to secure neatness and ample space in which to work and operate the equipment with safety.

All cables and equipment should be plainly marked showing the operating voltage and system it is used for. Where singleconductor cables are used on three-phase circuits they should be distinguished by different colors as this will prevent mistakes in making changes as only cables of like colors should be connected together.

While it is admitted that it is impossible to install a system that will be entirely free from trouble, it is possible, by carefully designing the system to prevent many of the faults that are a constant source of trouble on many systems.

Conduit System. The conduit system should be designed to serve the electrical distribution system as previously designed. This statement may, at first, appear to be a self evident fact, but unfortunately many conduit systems are not arranged to properly and economically provide facilities for installing the proposed cable system. It is not an uncommon practise to install a conduit system based on a general assumption of the actual requirements of the electrical system.

The writer has seen conduit systems in which it was absolutely impossible to install the distribution system as it had to be 
operated, and which had to be partially rebuilt before the cables and equipment could be installed. These are no doubt exceptional cases but it shows the importance of a definite method of procedure in designing an underground distribution system.

It is a common practise in designing conduit systems to select streets or alleys having the cheapest pavement in which to locate the conduit, and then attempt to fit the electrical distribution to this location, and the result is invariably unsatisfactory and the saving in the cost in repaving is frequently exceeded by the additional cost of cables, and the total cost of the system thus increased.

It should be realized that a properly designed and constructed conduit system is a valuable property, and a permanent structure having little or no depreciation, and its importance in the supply of electrical energy warrants the greatest care being taken in its design and construction.

Conduit systems that are to serve high-tension or tie lines between substations can be located so as to avoid the more expensive pavements, but conduit used exclusively for distribution systems should be located so as to best serve the electrical requirements regardless of the kind of pavement on the streets or alleys.

In a conduit system used exclusively for distribution (where all wires must be placed underground) the best location is usually in the streets. In cities having an alley in each block there is a strong tendency to locate the conduit in the alley.

The desire to utilize the alleys is based on the fact that the pavement is usually less expensive, and as the majority of pole lines are in the alleys the buildings are supplied from the rear, therefore if the conduit is located in the alley there will be less expense for changing the inside wiring to meet the new distribution system At first sight these advantages appear so great as to warrant the selection of the alley; there are, however, serious disadvantages to this location.

The alleys are usually from 16 to 20 feet wide and are generally fairly well occupied by water, gas and sewer facilities, and not infrequently, by one or two telephone conduit systems (which are usually installed before the electric light wires are placed underground) and the space available is, therefore, very limited.

The rear building line is very irregular, many buildings do not extend back to the alley, and frequently there are small sheds or extensions in the rear or the main buildings. The length of rear 
laterals would be greater than front ones and the difficulties and cost of installation considerably more; the greatest objection is that the rear laterals would not be permanent in many places but would have to be changed whenever any new building construction or changes were made.

Where alleys are located in the business section of a city they are usually used by the merchants for receiving and shipping goods and are subjected to a heavy traffic, considering the limited space. The merchants are practically all consumers of electric power and will strongly resent any interruption to their trucking facilities.

Owing to the limited space in the alleys, and the amount of traffic, it is practically impossible to store any material in them, consequently all material used on the conduit system must be stored in the adjacent streets and usually wheeled in by hand. This work and the excavation for manholes, removal of surplus material etc., will practically close the alley to traffic and the inconvenience of doing the work will greatly increase the cost of construction.

There is another serious objection to using the alleys. An average block, in cities having alleys, is about 300 by $300 \mathrm{ft}$. (91 by $91 \mathrm{~m}$.) and usually has at least twelve separate buildings in it, in the business section there are generally more. When the distribution system is located in the alleys all of the buildings in a block are supplied from one secondary main which practically doubles its size, and the number of laterals that must be connected to it require frequent handholes in order to reduce the length of the laterals. This entails more complicated and expensive splices, cuts the main into short lengths, and in case of serious trouble puts the whole block out of service.

As a general rule, with the single exception of requiring less conduit, the alley construction is less desirable than a system installed in the streets. This statement applies to the business district of a city. Where overhead laterals can be used in a residential section the alleys are preferable for the location of the conduit, and as the traffic and obstructions are usually considerably less in such sections, the construction cost will be correspondingly less, depending on the pavement.

Before making the conduit design it is necessary to plot the location of all car tracks and existing sub-surface obstructions, in order to determine the most suitable location for the new system. While it is known that the records of sub-surface con- 
ditions are seldom accurate still a study of these records and the location of water gates, sewer manholes and other surface indications will permit a fairly accurate map being prepared.

Where there is any doubt regarding space being available for the conduit and manholes it is advisable to dig test holes, and if possible they should be dug at the points where it is proposed to locate manholes.

The design of an underground distribution system is not a difficult matter if handled in a systematic manner and the result obtained from a thorough study of the conditions will fully warrant the engineering expense necessary to prepare accurate plans covering every detail of the work. 
Discussion on “Underground Distribution Systems" (Newton), Chicago, September 20, 1916.

T. E. Tynes: This most excellent paper, prepared by $\mathrm{Mr}$. Newton, and so very ably presented by Mr. Gear, covers the question of underground distribution of energy in a very broad way. Mr. Newton has given a great deal of time and thought to this question of underground distribution, and while the paper applies particularly to the distribution of energy in cities and congested districts, such as we have here in Chicago and in other large cities, the principles involved are applicable to any underground system which we may have occasion to use in steel mills, such as the construction of conduits, the making of joints, the position of switches, etc.

Alfred F. Hovey: A great deal of time might well be given to the discussion of this paper as regards the detailed construction of the conduits and cables. There is one statement which involves a rather dangerous point; the author states: "Where triplex-conductor cables are used on three-phase circuits, they should be distinguished by different colors as this will prevent mistakes in making changes, as only conductors of like colors should be connected together." I have personally encountered a good deal of difficulty from just that kind of a specification. It is almost next to impossible to make joints that will be serviceable for a long term of years, such as good joints should, and at the same time secure the matching of colors. The time has come when we are using large conductors in sector form, and under those circumstances it is still more difficult to match these colors. Very often it requires one of the conductors to be drawn through and between the other two conductors in order to match the same color, and there is no safe way of identifying the conductor and be sure you are right, except by making a test one way or another, without possible damage to the insulation. Jointers find they cannot make as good a joint where they attempt to match the colors. The cable has to be manufactured in a certain way, so that the lay is all one way, and the cable has to be pulled in, in a certain direction, and sometimes it is impossible to feed the cable into one of the manholes, but it has to be pulled by means of a series of blocks and tackles, but if the cable is not drawn in exactly right, it is extremely difficult to straighten out the lay of the conductors at the joint, so to match the conductors, although it sometimes happens; but then it is a matter of chance. That is one point which I think it might be well for engineers to avoid in making up specifications to secure a perfectly satisfactory operating system.

Another point where the writer of the paper says: "Personally, the writer does not approve of using any paper-insulated cable on the distribution systems, except in cases where the emergency facilities are such that the failure of a feeder cannot cause a serious interruption to the service." Several managers of works 
with which I am concerned at the present time, are installing paper-insulated cables both for economy and for good operation. A paper-insulated cable requires slightly more careful installation, but if properly handled, I believe in many cases that it will make as good insulation as either the rubber or varnished cloth insulation. It has been my experience that recently the majority of engineers specify paper cable. There is no particular reason for bringing up that point, as nearly all cable manufacturers are prepared to furnish either rubber or varnished cloth or paper insulation on their cables.

Just a word of commendation to Mr. Newton, who has had considerable experience along this line for years. We have known him, particularly in conduit work, and in cable work for years, and I believe that this paper will be of great assistance to engineers in laying out either a large or small system, because it gives the basis in foundation of fact for a specification that would provide a satisfactory operating system.

Not having read this paper carefully enough to know whether any mention is made of a scheme used considerably nowadays, that is to run the trunk ducts underneath the service boxes, I would say that this is an important feature in designing space for trunk feeders and secondary mains by building a handhole over the top of the lower trunk conduits and taking in only the top ducts, using them for distributing mains and secondary feeders. That is a point on a small system that is particularly important, as it cuts down the original cost of the conduit system materially. In that way, the small conductors can be exposed through these handholes for taps and the handholes can be constructed at very small cost and at large insurance over the other scheme of opening all the ducts into all the manholes.

There is one manhole that has cost, as I was informed last week, about $\$ 10,000$ because the engineers originally did not make the manhole large enough. The manhole has been rebuilt eleven times, with the consequent cutting of cables and re-racking them around this constantly enlarged manhole. One of the operating engineers told me not long ago that his company was expending over $\$ 150,000$ a year rebuilding manholes. That is a point that the engineer, in laying out an underground distribution, might well keep in mind, because it is well known that the cheapest real estate is that which you enclose by a manhole wall under the street. By making a large, generous manhole, you have plenty of racking space for the cables on the sides, with sufficient room on the side-walls for proper racking and proper bending, and the original installation will take care of the operation in the future much better than having to rebuild the manhole at considerable extra cost.

F. D. Egan: My experience with underground conduit work has been entirely in the steel plant, and I could not discuss $\mathrm{Mr}$. Newton's paper from the standpoint of city construction. We have installed approximately 125,000 feet of underground 
conduits in our steel mill, and as far as the matter of trouble goes, I find that the underground system is more reliable and more dependable than the overhead system.

Another point that Mr. Newton brought up regards the high cost of underground versus overhead. While that might apply in city construction, if compared to the type of construction to be used in a steel mill, the cost is in favor of the underground. When we distribute power at 6600 volts, or higher, for safety reasons we would construct duplicate power lines and the cost of this would be higher using bare copper pole lines than it would be with underground system and lead-covered cambric cable.

That is the experience we met with in our construction. We have been operating on this system in some of our plants for from three to four years, and so far we have experienced no trouble from an electrical standpoint. We lost two cables adjacent to the power house, which ran parallel with the old buildings, and the trouble there arose from the discharge of steam traps; this heat entered the conduit system, raised the temperature and the additional electrical load caused a breakdown. After we removed the steam trap discharge, we experienced nó more trouble.

Another advantage of the underground system is the point of safety. We have there the point of totally enclosing the electrical distribution line, and the one point which would come up there, regarding safety, would be care in determining the proper line to work on in case of opening up of the cable.

S. C. Coey: Mr. Newton has given us a very interesting description of the methods used in laying out an underground cable system for a city and has pointed out many of the valuable features of such an installation. While many of the fundamental principles are the same, when we apply these data to an industrial plant system and especially a steel plant installation in which most of our members are most interested, we have a special application which calls for special treatment.

Installations in steel plants are more analogous to subway equipment than to any other type considered in the paper. The liability of having underground ducts filled with water is always present in those steel plants built on the banks of rivers having a large rise during flood periods. This applies to most of the plants in the Pittsburgh and Youngstown districts. Where plants are installed under these conditions it is usual to make the yard level only a few feet above the maximum high water. This is done from practical considerations as every increased foot that the plant is above normal water level means that many more foot pounds of energy expended in pumping the large amount of water necessary in the modern steel plant. This condition makes it necessary to lay out a duct system with the idea in mind that the cables are subject to the liability of being under water at some time. In plants of this description the use of underground 
transmission even with varnished-cambric lead-covered cables is subject to possibilities of trouble that are serious and makes the advisability of installing it very questionable.

In transmitting alternating current in lead-covered cables it is advisable to confine all three phases within one lead sheath. When single-conductor lead-covered wires are used for this work there is considerable loss and possibility of trouble from sheath currents. If the sheaths are bonded the $I^{2} R$ loss from the sheath currents amounts to about half the normal $I^{2} R$ loss in the copper conductors so that this method of operating is inherently inefficient. As it is usually impractical to insulate all the cables from one another and impossible where flood conditions are to be met the three-conductor cables should be used. In this case we have all the heating effect confined within one sheath and cable ducts must be carefully watched to see that there are not points where they get excess heating from external points.

I have also pointed out in a paper before the Association of Iron and Steel Electrical Engineers that where grouped ducts are used, the heating effect from a center duct to adjacent outside ducts with only radiation to take care of heat dissipation is cumulative, as shown by the result of tests, and for this reason ducts should not be made more than two ducts wide.

In underground ducts around steel mills as I have noted before it is often found that the ducts are heated from some external source. This is usually when the duct passes close to heating furnaces of some kind, which are impossible to get away from entirely in this class of work. This type of service calls for special study in each case. In some cases forced draught through the ducts have been used with good results. I have found for this work that varnished cambric insulation is the only type that can be relied upon as the heat affects rubber very rapidly.

While an underground system is usually spoken of as the most permanent system, and is, in the ducts proper, I would raise a question when we consider the wire insulation, as air and porcelain are more permanent than paper, rubber or varnished cambric and these are the materials depended upon in the two systems respectively to maintain the insulation of the circuit:

The principal advantage gained by the underground system is the freedom from liability of trouble from lightning, pole failure, and obstructions against wires.

In steel plants the locomotive crane problem is the most serious in the last item.

The advantages the overhead system has over the underground system are flexibility, initial cost, wire insulation and speed of location and repair of trouble.

As I see it, both systems as used today have their drawbacks and for a steel plant installation I believe that the ideal system of transmission would be to have an open concrete duct with reinforced concrete roof, well ventilated, with insulated cables strung on porcelain insulators so arranged that an inspector 
could walk through the duct. This could be entirely underground where the high water mark allowed, or in some plants could be above ground and used for a line fence. This system of installation would give the advantages of both the present systems without any of the disadvantages.

T. E. Tynes: We have quite an extensive duct system, originally installed about ten years ago. Our plant is built on land that was a swamp and there is a great deal of filled-in land. We have experienced some trouble due to the settling of the ducts. In locating a duct line, especially in steel plants, great care should be taken that this line is installed where it will not be interferred with by future construction, as it is a very difficult matter, after a duct line is installed, to have to rip it up to make room for a new mill going in, or some other consideration arising, which is of sufficient importance to cause the ripping up of the duct system.

The selection of a suitable foundation on which to build the duct line is very important, as I mentioned the trouble we have had due to the settling of the land. We have had some cable nearly cut off due to the settling of the ground.

The type of duct, or material out of which the duct line is constructed, is also important. In our plant we constructed every circuit of vitrified duct, and we had some difficulty with cracking joints which has allowed one thing and another from the ground to come in, and these substances have eaten off our lead coating right where the joints are. We have been troubled considerably by electrolysis, and upon taking out cable we have found pinholes, hardly visible, and they would let water into the cable.

Another important thing is making the splice. To make a good splice you should have the joint thoroughly filled with a compound, allowing no air bubbles to be formed, as in time the air bubbles will cause deterioration of the insulation and produce a breakdown. We do not know the reason for it, but we have opened up joints and found where the air bubbles destroy the insulation, and that increases until it gets to the lead sheath and then the cable breaks down.

We use paper and lead-covered cables. We have had them in operation now on 2200 volts for ten years, and have had no trouble at all with this voltage. We have had trouble on our low-voltage cable due to electrolysis and improper making of the joints.

All of our 2200-volt circuits are underground, also a great deal of our 440-volt circuits and 250 -volt circuits. We are now taking the 250 -volt circuits and the 440 -volt circuits and putting them overhead.

We feel that where an overhead line is properly constructed, good insulators, and line put up in a permanent way, that it is much better for transmitting low voltages than the underground system. There is less trouble, and what trouble we have can be seen and taken care of before it is too far advanced. In 
the case of the 2200-volt circuits, the question of safety comes in, and we put those circuits underground for that reason.

C. A. Menk: I do not think I have very much to add to the paper. It is very interesting. What are you going to do with your present installation? You have an old plant, and if you are going to add to that, what will you adopt? The first question which comes up is: "You have gone along for years with your overhead construction. Is it going to pay to put it underground?"

Another thing; in designing a new plant $I$ think it will be actually necessary to know what is going to be added in twenty years from now, if placed underground, because it is hard to tell what may develop and how soon it will develop. As Mr. Tynes said, to make extended changes would be very expensive. Take a city like Chicago and other large cities. These cities are well established, and underground work can be put in that should be good for twenty-five years, probably fifty years, especially in the residence districts, but in the case of mill work it seems as if one would have to look ahead and make very extensive provision for added improvements in the future.

In installing an underground system on three-phase work, will it be advisable to put in the triple conductor, or single it out and put it in, in triangle form?

In installing underground work, would you put in a conduit system large enough under the present day engineering, so that you could pull out the cables and put in larger ones, to avoid having to rebuild your manholes? One of the speakers said that in one case the manhole was rebuilt eighteen times. To me that looks like very poor engineering.

T. E. Tynes: In reference to Mr. Menk's question, whether to install triple conductors, or single conductors, all our underground cable is three-conductor, even the 2200 volt up to 500,000 cir. mils, and as I said before, we have had no trouble from the insulation of the cable - it has all been joint trouble and electrolytic action on the lead sheath.

S. C. Coey: I have had some experience with an installation on which single-conductor, lead-covered cables were used on three-phase work. On investigation it was found that where the lead covers of the cables came in contact, the sheath currents made pin-holes in the lead and when moisture was present paper insulation absorbed it like blotting paper. In my opinion it is a good thing to keep away from single-conductor alternatingcurrent transmission.

H. B. Gear: You referred to low tension, I suppose?

C. A. Menk: Yes, 440-volt circuit.

H. B. Gear: I quite agree with the suggestion that the cables carrying large current should be multiple-conductor in form. A case came to my attention just recently, in an industrial plant - not a steel mill, but a condition which is very similar - where there were thirty-two No. 00 cables that had to be 
carried a distance of 800 to 1000 feet from the plant to the point where the power was used, and in order to keep down the inductive drop on these circuits they had made them small, but they were all overhead, and the drop was something like 33 volts on a 220 -volt system in that distance. If these cables had been placed underground and made three-conductor, with a separation of only perhaps an inch between centers, the inductive component of the drop would have been very much less and the system would have been far more satisfactory. As it was, they were unable to use any additional power at the other end of the line without stringing more copper, for which room was not available on the poles.

In general, single-conductor cables are somewhat preferable for high-tension work where the lines are used for distribution purposes, that is what Mr. Newton has called secondary feeders which are really primary distributing mains.

Where joints must be made more frequently, for connecting in transformers, it is easier to do that work on single-conductor than three-conductor, from the fact that the opposite polarities can be separated. Frequently that work has to be done on either live, or very close to live wires. In general, the cost of three-conductor cables is sufficiently less than single conductors, to warrant their use, often at the expense, as is sometimes done in manholes or other places where taps are made, of fanning out into three singles. If the manhole lengths are long, say four hundred or five hundred feet, it is usually cheaper to make an extra wiped joint in the manhole, going through with singles, in order to save the cost of extra lead that would be put in the conductors in the long cable line.

In regard to paper insulated cables, Mr. Newton's statement is very well considered. He agrees they should be used and can be used where experienced men are handling them, but his statement is that they should not be used where inexperienced men are handling them. In a large system, such as that in Chicago, we use nothing but paper cable, even for laterals and secondaries.

There is no difficulty whatever with high-tension cables in taking care of ends if they are provided with potheads, as Mr. Newton suggests.

With regard to the facilities which are provided for in emergencies, the pot-head is so arranged that it is an easy matter to have one cable act as a reserve for a group of cables, doing the same class of service, and the developments in recent years are quite numerous as compared with what we used to have to get along with in the way of emergency facilities.

In connection with the ventilation of transformer rooms, I notice that Mr. Newton suggests that any transformer room for 200 kilowatts or more should be ventilated. Our experience is that is rather a high limit. We have had a number of cases of 150 or 120 kilowatts, where in the summer time the ordinary air 
temperatures, especially like we had last summer, were enough to make these transformer rooms run up to 130 to $140 \mathrm{deg}$. fahr., and the oil temperatures correspondingly high, so that the insulation was in danger. It takes rather a liberal ventilating system in the form of intakes and ventilating flues, etc., to take care of such an installation during warm weather conditions, especially where the transformers carry load continuously on power installations.

With regard to the size of conduits, I think that especially where secondaries are to be run, and where a three-conductor cable is advisable, the conduit should be at least four inches in diameter. We have had considerable difficulty in Chicago, because of the fact that many years ago we adopted a three and one-half inch conduit as our standard size conduit. When we get up to the point where we would use large three-conductor 20,000 -volt cables, we are limited to a diameter of three and one-half inches in the ducts, and 250,000-cir. mil cable is the largest we can get into it. That leaves about one-quarter inch clearance which is the least that is practicable, and lengths between manholes are limited to 350 feet in order to allow the cable to be pulled in.

In any case where large low-tension cables are to be used and where three conductors are desirable, I would advise that a 4 -in. conduit would be advisable.

B. G. Beck: We have been working with one of these underground systems for a long while. I think when we put in an underground system we should take into consideration the condition of the soil. We have one that the hotter it gets the more it leaks, and the more it leaks the hotter it gets. A great deal of the heating depends on the depth of the installation.

As pointed out, we should take into consideration the proximity of the furnace gas mains and hot water return mains, which may be installed, and another trouble we got into was in following the standard practise that ordinary city engineers used in putting in their duct system. They have really an intermittent service, a period during the day in which their heat goes into the duct systems, and during the night it can be cooled off before getting another big load in the morning, and adding more heat to it. With our system, it is a steady service, six days in the week, and we add heat all the time, and that makes our service quite different from city service.

As to using 16 or 20 ducts in a line, I do not believe I would do it, with the amount of power we have to use in these ducts.

In regard to sectionalized ducts, it is difficult to run the ducts through the steel mill in any case. In most cases you have to run it between furnaces, and when you are running from one center of distribution you cannot sectionalize your ducts.

We ought to take into account the effect of one cable transmitting trouble to another. I believe that has been taken care of by these gentlemen in a very nice way. 
I have been thinking of taking out the old duct system, and making a runway through the plant, with a reinforced cover over it, and ventilators about every twenty ft., with air ducts so arranged that we can utilize a fan in case of burnout. We had a serious burnout some time ago when the cables were up to 120 deg. cent., even those cables which were not carrying current.

With all the troubles to which the underground cable system is incident, there is one thing we must take into account. We have been transmitting about 15,000 kilowatts, 2200 volts, underground, and we have not had any loss of life. The prevention of such loss of life was the primary object in installing an underground system, and we also have not had any motor losses on account of storms or lightning. On some overhead systems with which I have been connected, and on one system in particular, we had a bad lightning storm and lost fifteen motors at one time. That kept us busy for some time. A couple of those motors were big ones on which the plant depended. We have not had any trouble of that kind, but have had trouble with cables. Some of them have been minor troubles, and only one very serious trouble, and the trouble I refer to now was in the case of a cable which started to go bad, and affected the adjacent cable, and that affected the rest of them, and we had our whole duct system hot.

Regarding the running of these wires underground. As was pointed out, when you support the individual cables on porcelain insulators, the question of induction comes in, and it is a question whether with large current carrying capacity we would not run into a lot of trouble with this induction effect, it might be better to install the lead covered cables in a duct system where you could go into it and ventilate it and get your gases out, in case they did blow up.

Barney W. Gilson: I would like very much to hear something from Mr. Gear in regard to the limitations as to size of threeconductor cables. It has been my experience that three-conductor cables larger than $500,000-\mathrm{cm}$. are very difficult to handle and install, however, we now have two 500,000-cm., 3-phase cables in operation, and have some 700,000-c.m., 3-phase cables on order. These last will be laid in floor duct, and not pulled through conduit, as were the $500,000-\mathrm{cm}$. cables.

Ludwig Hommel: Mr. Coey's plan of a tunnel on the ground instead of under the ground, looks very good, where it is possible to put up such a structure. In fact, I had wondered whether a conduit system with ducts laid on the ground in a few inches of concrete with handholes where necessary might not be feasible in mills having ground water near the surface.

Where a tunnel is used, the cables should be covered for their entire length, just as is done now for the exposed part of the cables in the manholes. It would be interesting to have $\mathrm{Mr}$. Hovey tell us what is the latest practise, what material is now 
used for that purpose. If porcelain insulators are used for supporting the cables, the lead sheaths should be grounded to avoid any possible danger to the men handling or touching the lead sheaths.

The planning of the manhole layout is important to avoid unnecessary crossing over each other of cables in the manholes. If a diagram is made of each manhole before the cables are drawn in, showing how the cables will run across ultimately when the duct system is filled, it should result in much better work and avoid trouble in the manholes.

The trouble with cables, if there is any, generally occurs in the manholes where the cable has to be bent-the bending of a cable is an operation that requires skill and experience. If a burnout occurs, it is most likely there to involve other cables.

I believe that junction boxes were mentioned in the paper. It is my experience that they are a source of trouble, while joints are practically as safe as the cable itself.

I agree with $\mathrm{Mr}$ Hovey on the paper insulated cable. I believe that it is fully as reliable as rubber cable and the joints are at least as easily made, and perhaps more easily and safely than on rubber cables.

George T. Street: There is one point which has been brought out in regard to manholes: the tendency in the past has been to make the manhole too small. But there is another point which has not been mentioned, and I think it is important: the tendency to make too few manholes. Each additional manhole means additional jointing, but it means much less liability of mechanical damage to the cable in installing it on account of reduction in tension while drawing in, and I think that is one point which should be carefully considered in laying out any conduit system.

Fred H. Woodhull: There is one thing that will have to be guarded against pretty carefully in using the tunnel system. The tendency, where the cables are carried on concrete carriers, where they carry heavy currents, is to have them clamped in some way. They must be held, due to the magnetic effect. I call to mind an experience I had some years ago in connection with central station work in New York City, where a short circuit occurred back of the switchboard, causing some large lead covered cables to jump off of the cable racks. It is a thing which will have to be guarded against.

A. F. Hovey: In one of the oldest and best known methods for fireproofing cables in manholes against the explosion of adjacent cables, common rope and concrete are employed. The former is wound spirally around the cable with about $1 \mathrm{in}$. separation between the turns, and the cable and rope are then plastered with a one to one mixture of sand and cement. The rope provides a rough surface to which the concrete clings readily and gives a slightly flexible back-ground, which aids somewhat in preventing cracking of the fireproofing under a chance blow.

The workmen's hands have proved to be better than any tool 
for applying the cement for this type of covering. As far as the fireproofing qualities alone are concerned, this covering is satisfactory, but its removal presents a formidable task. Efforts to reduce this difficulty have been made by placing the turns of rope closer together and, except for the fact that rope is now rather expensive, this method of protecting cable is fairly satisfactory.

Another method of fireproofing is that in which asbestos millboard, cut into 3 -in. strips, is wound around the cable and held in place by a fire proof paste, silicate of soda. This covering proved satisfactory as long as the manholes remained dry, but if water ran in and covered the cables, the silicate was dissolved and the asbestos loosened, dropping from the cable. Recently, on account of the difficulty in obtaining deliveries of asbestos millboard, asbestos listing, a woven material with a selvage has been substituted. This material can be purchased in the form of 3 -in. tape and wound spirally around the cable, and the silicate of soda covering is used to hold it in place.

When material as expensive as asbestos is used for fireproofing cables, some provision should be made for salvaging the covering when it is removed from the cable. A simple and inexpensive way of doing this is first to wrap the lead sheath of the cable with strips of cheesecloth dipped in paraffine. One layer of cheesecloth is sufficient. Then when repairs are necessary, the asbestos can be separated easily from the paraffined cloth and taken off in long strips. If these strips of asbestos are carefully rolled backward during removal, they can be preserved and reapplied.

In what is perhaps the most recent method of fireproofing underground cables, a layer of paraffined cheesecloth is wound around the sheath and over this metal lath, covered with cement and cut into strips, is spirally wound. The cloth is applied as described above, simply to aid in removing the covering. The metal lath used is a wire mesh covered with brick-clay put on under pressure and baked, the resultant product being a web of small briquettes which can be applied the same as any wire or expanded metal lath. This makes an excellent foundation for the cement mortar, as it is porous and flexible. The cement can be applied with a trowel or by hand, forming the covering into a homogeneous mass. While this type of covering is somewhat more difficult to install than the asbestos covering, it is considerably less expensive, as calculated from the prevailing prices of material. It can easily be removed by breaking the cement covering with a hammer and cutting the metal lath with tinner's snips.

Whatever covering is applied should be considered good insurance against both mechanical and electrical trouble. The added application of paraffined cheesecloth under any of these types of covering insures the lead sheath against damage at the time the covering is removed for changes in the manhole cables. 
I would add one more point in regard to the fireproofing. In constructing the manholes, the scheme of putting in slate slabs to carry the cable and the joint through the manholes, particularly in the oblong or egg-shaped type, seems to be a particularly desirable addition to the conduit system itself. It gives a good support, whether the cables are wrapped or not, from one mouth of the duct to the other side. It saves putting in a lot of hangers, and can be installed by putting in T-irons along the wall and the stone or slate slab can be in three pieces, one long piece under the joint, and a section on each side of the joint, and furnishes a good protection from one cable to the other.

T. E. Tynes: One speaker brought up the question of the number of manholes to install for the duct line. Be sure to get enough. In our new lines we do not bring out all cables in the same manholes, but only bring out one-half to alternate manholes. If we lose one set of cables in a manhole, we are only incapacitated to half the capacity of our cables.

We have also used the method of wrapping asbestos tape around them to protect them in case of a ground, and that is effective except where there is gas in the manhole. We have had several bad fires due to leaky gas mains near the conduit line, and the system would fill up with gas, and that gas would destroy anything put in.

If a partial ground occurs on one of the cables, the asbestos covering in the case of dry manholes is sufficient protection, but this will not work where there is dampness.

H. B. Gear: In regard to the subject of cable protection, we have used the rope and cement wrapping in Chicago for several years now, and I think we have avoided the trouble Mr. Hovey spoke of, (of having the cement stick too tightly to the lead sheaths) by using rather more rope than he described, that is, wrapping the rope so that the spirals almost touch each other. There has been little difficulty in breaking off the rope and cement when it was desirable to get at the cable to do work on it.

There was one point raised about the maximum number of ducts referred to - twenty ducts. I might explain, further, that when anything over perhaps nine ducts or ten ducts is put into one line, it is the practise in Chicago to separate the conduit system into two halves by putting three inches of concrete between the two ducts on one side and the two ducts on the other side, never putting more than four ducts in any horizontal row, and no duct is more than one duct away from the outside earth, from radiation. This additional barrier of concrete between the two halves of the system is then carried into divided manholes where the number of cables is sufficient to fill the duct system, and not more than eight or ten cables in that way go into any one manhole. The manholes are built in a staggered form, onehalf of the conduit system going into one and the other half into the other. 
In the vicinity of power houses, where large numbers of cables must be brought out, this problem was solved in our most recent installation by the use of 24-duct runs. These 24-duct runs came out of three or four different busses, and fanned out into 4-duct lines, going to a series of manholes which led out from three different conduit systems. Three conduit systems went in different ways to the station, and by doubling the manholes on each of the conduit systems, and fanning out a group of 4 from each of the 24 into the manhole, all of the cross-overs were taken care of underground and a system was devised by which a cable could be brought into any conduit system or by which we have no cross-over in any manhole.

With regard to the maximum size of conductor which might be put into a 3 -conductor cable, I do not know that I can answer the question specifically. I have known of cables as large as 600,000-cir. mils being used. The real limit, I think, as I stated before, is in the size of the conduit which is used. With a 4 -inch conduit system, I think there will be no difficulty in using three 600,000 -cir. mils or possibly three 750,000 -cir. mils conductors in one three-conductor cable.

In reference to using a tunnel large enough for men to walk through, I would be inclined to think it would be preferable, even if such tunnels were used for low-tension cables, to use 3 -conductor cables carried on a rack rather than to use single cables carried on separate racks which would necessarily have to be three or four inches apart. The inductive effect as well as the safety of installation, would be bettered by the use of threeconductor cables. 